\title{
Design and Application of Educational Display Based on Holographic Immersion Technology
}

\author{
Yi-qiang $\mathrm{Jin}^{1,{ }^{*}}$ and Wen-juan $\mathrm{Lu}^{1}$ \\ ${ }^{1}$ School of Cultural Communication and Design, Guangdong Open University, Guangzhou, Guangdong 510091, China \\ *Corresponding author. Email:hellojinyiqiang@qq.com
}

\begin{abstract}
In order to endow knowledge with richer presentation and enhance the sense of participation in learning, The purpose of the paper is to apply holographic immersion technology to educational display. This paper selects the landmark "Zhenhai" building in Guangzhou as the object of education exhibition. By constructing threedimensional models, textures, baking efficiency and rendering output, the 3D image of Zhenhai building, which contains educational significance, is visually visualized in real scenes, forming a strong immersion effect. The survey shows that holographic education display can significantly improve the display effect compared with traditional education displays.
\end{abstract}

Keywords: Holographic immersion technology; Education exhibition; Design and Application; Zhenhai

building

\section{INTRODUCTION}

Holographic immersion technology, also known as holographic projection technology, is a technology that records and reproduces the real three-dimensional image of an object by using the principle of light interference and diffraction[1]. Holographic immersion technology can not only produce three-dimensional aerial illusion, but also make the illusion interact with the participants to produce a shocking three-dimensional effect[2].

The field of education has been pursuing the image expression of knowledge, seeking a richer way to present knowledge, so as to enhance the interaction and participation of learning which makes knowledge and information could be more effectively accepted and absorbed by learners. The traditional education display is mainly realized through print works and physical models, which makes its performance ability relatively poor and limited.

However, with the help of the powerful virtual reality ability of holographic immersion technology, the new educational display design can realize the three-dimensional images containing educational significance suspended in the real midair imaging, forming the fusion of virtual educational objects and the real physical world, creating the effect of both fantasy and reality, and greatly enhancing the educational display ability[3]. At present, the using of holographic immersion technology for educational display design belongs to the forefront of industry development, which has great research value.

Therefore, this paper combines holographic immersion technology with educational display, and takes the holographic display of museum exhibits as an example to explore the design method of educational display based on holographic immersion technology.
The existing scheme can overcome the problem of poor performance of traditional education display methods, at the same time, it can see real three-dimensional objects and space without wearing augmented reality glasses or virtual reality helmet, greatly enhancing the effect of education display.

\section{EDUCATIONAL DISPLAY DESIGN BASED ON HOLOGRAPHIC IMMERSION TECHNOLOGY}

Museums generally use on-site physical display, supplemented by text introduction. This kind of exhibition belongs to static display, with single angle and poor interactivity, which is difficult to leave a deep impression on visitors[4].

Holographic immersion technology includes holographic glasses, holographic screen, holographic projection and holographic display cabinet[5]. The holographic glasses have built-in CPU, GPU, stereo technology and holographic processing unit. It can appear in front of the user's eyes suspended interface to process real-time and virtual information. Microsoft's HoloLens is a typical example of the holographic glasses. Holographic screen is a kind of screen material used for holographic projection. The advantage of holographic screen is that it can be installed flexibly, which could be spread or folded. At the same time of high light transmission, holographic screen can ensure beautiful picture, bright and full color.

In this paper, the holographic display cabinet with high cost performance and flexible layout is used as the museum education display equipment; at the same time, the landmark building "Zhenhai building" in Guangzhou is selected as the display object. Zhenhai building is located in Yuexiu mountain, Guangzhou City, Guangdong Province, China. It is a national key cultural relic protection unit, which was built 
in Hongwu Period of Ming Dynasty. After five destruction and five construction, it was renamed Guangzhou Museum in 1950, which has high educational significance.

Holographic display cabinet is mainly composed of cabinet, spectroscope, spotlight and video playback equipment. First, build a three-dimensional model of the object, and then superimpose the model into the real scene to show the details of the product vividly, which will bring a strong visual impact to the audience and deepen the understanding of the product. The mapping video of holographic display cabinet needs to contain all four angles of the object in one video file[6]. But one camera can't irradiate two angles at the same time, so we first use four cameras to irradiate the front, back, left and right angles of the object at the same time. After rendering, the four videos are imported into the later software for adjustment, and all the contents of the four videos are contained in one video. Then a square video file is exported, and a three-dimensional object is mapped by the holographic projection instrument.

\section{EDUCATIONAL DISPLAY PRODUCTION PROCESS BASED ON HOLOGRAPHIC IMMERSION TECHNOLOGY}

The holographic display production process of Zhenhai building includes: firstly, determine the architectural layout and size of Zhenhai building; secondly, carry out the main body modeling, mapping and lighting; finally, render and place the display film, and display the projection system.

\subsection{Display Subject Modeling}

The first step of holographic projection is to make the model of indoor real scene display, that is, to use the threedimensional production software to build the model with three-dimensional data. 3D modeling can usually be made by using 3dsmax, Maya, rhino, C4d and other software. The modeling tool used in this paper is Maya. First, the Zhenhai building image is imported into Maya for freezing, and the capture point is set to the vertical and midpoint to become the base map; the production entity, with the help of the base map, starts the interior decoration after the overall structure is made; the modeling is modified, and the details are checked and modified after the modeling is made.

When building a model, developers should pay attention to the proportional relationship between objects and the number of faces of the model. The three-dimensional model produced by computer software is composed of polygons. A polygon can be identified as one side. Traditionally, the number of polygons in a three-dimensional model is called the number of faces, that is, the number of faces in the model. The more facets of the model, the higher the requirement of computer performance.

At the beginning, we made it according to the high-precision model. As a result, the "Zhenhai building" produced more than 4 million faces, which made the real-time display machine unbearable. So later, the developers painfully reduced the number of faces of the "Zhenhai building" model.

\subsection{Mapping}

The second step of holographic projection is to map the model. When mapping, first expand the 3D model into a plane, then draw the material map in Photoshop and other 2D software, and finally use Maya, 3dmax and other 3D production software to cover the material map on the 3D model. Whether the model can achieve the pre designed display effect is closely related to the given material. Material can be seen as a combination of material and texture, such as texture, transparency, smoothness, luminosity, etc. with these visual attributes, we can identify what the model is made of.

\subsection{Lighting Debugging}

After completing the work of 3D modeling, map drawing and so on, lighting and color adjustment should be done. If the model is the five senses of the building, then the light is the soul of the building. Good lighting can improve the texture and reality of the picture, making the objects in the picture more real and life[7]. Three point lighting is the most commonly used lighting method. Three point lighting, also known as regional lighting, generally has three lights, namely main body light, auxiliary light and contour light. Three point lighting, mainly used for small range of scene lighting. If the scene is large, it can be divided into several smaller areas for lighting.

The work can be done by the Maya light rendering. In addition, the lighting plug-in can be downloaded for lighting debugging.

In general, lighting plug-ins are more popular with users. Compared with the Maya built-in lighting effects, lighting plug-in will make the operation more simple, does not require the use of more parameters and complex command can achieve better results. After loading and installing the plugin, you can directly click on the command to modulate the incident and set up a good light for yourself. So, with the help of the plug-in, it can be done better and faster.

This paper uses the Maya V-ray plug-in for lighting debugging. V-ray is a commonly used and very powerful lighting plug-in, which is even better than the Maya with mental ray in the lighting effect.

\subsection{Post-production}

For video production, post-production is an essential part. Most of the video in the pre production process due to various factors can not achieve the effect of film, must be through post-production, color matching and other aspects to complete[8]. Similarly, the production of holographic projection is also indispensable in the later stage. In this paper, we use Adobe premier to clip video, cut out 
unnecessary parts, and then import them into Adobe After Effects to make special effects and color matching.

After the film came out, it entered the holographic projection link. The rendered video is originally a plane effect, which needs to be projected into the pyramid. In the projection of the video, it is necessary to have four sides of the object, namely front, back, left and right. But a camera can only irradiate one angle, so this paper uses four cameras to irradiate four angles of the object. After rendering into four videos, in Adobe premier, using the clipping effect, the four videos are pieced together in a square video. After rendering, the video file can be projected into the instrument to complete the final step of holographic projection. The omni-directional display effect can make the details of Zhenhai building at a glance.

\section{RESULTS AND DISCUSSION}

\subsection{Design and Distribution of the Questionnaire}

In order to understand the application effect of educational display based on holographic immersion technology, the paper designs a questionnaire of "holographic educational display effect". Before the questionnaire issued, three teachers of primary and secondary schools in Guangzhou are invited to test and comment. Finally, according to the comments of the test, some amendments are made to ensure the validity of the questionnaire. Then, the paper selects the information technology teachers who are sensitive to new technology to send out the questionnaire, and finally returns 67 valid questionnaires.

\subsection{Statistics of the Results of the Questionnaire}

The basic information mainly includes the age and gender distribution of the respondents, the position of the school, the teaching period, the nature of the work and the understanding of the holographic education display. Among the respondents, 12 people (17.9\%) had less than 3 years of teaching experience, 25 people $(37.3 \%)$ had $4-8$ years of teaching experience, 20 people $(29.8 \%)$ had $9-15$ years of teaching experience, and 10 people (14.9\%) had more than 15 years of teaching experience. There were 43 males $(64.2 \%)$ and 24 females $(35.8 \%) .8(11.9 \%)$ came from primary school, 14 people $(20.9 \%)$ from junior high school, 39 people $(58.2 \%)$ from senior high school and 6 people $(8.9 \%)$ from university. There are 12 people educational researchers $(17.9 \%), 49$ fulltime teachers $(73.1 \%)$ and 6 people educational administrators $(8.9 \%) .100 \%$ of the respondents experienced the display of "Zhenhai building" based on holographic cabinet before filling in the questionnaire.

The display effect of holographic education is considered from the aspects of image, ease of use, stability and interactive means. The questionnaire was designed by Likert 5 scale, and the subjects were selected according to the degree of agreement.

As can be seen from table 1, "Zhenhai building" holographic education display is very image, simple and easy to use. The vast majority of respondents $(95.5 \%)$ thought that the holographic display of "Zhenhai building" was very clear; $82 \%$ thought that the combination of holographic display and real scene had a sense of substitution; they thought that viewing holographic display with naked eyes was very convenient and intuitive; 95.5\% said that "Zhenhai building" supported multi angle holographic display.

"Zhenhai building" holographic education display has high stability and rich interactive means. $98.5 \%$ of the respondents said that they could quickly switch the display angle of "Zhenhai building"; 94\% of the respondents said that there was no jam in the display process, and the voice explanation was convenient for users to understand "Zhenhai building"; $95.5 \%$ of the respondents thought that it was useful to zoom in and out of "Zhenhai building".

Table 1. Holographic educational display effect

\begin{tabular}{|l|c|c|c|c|c|}
\hline \multicolumn{1}{|c|}{ Survey items } & $\begin{array}{c}\text { Strongly } \\
\text { disagree }\end{array}$ & Disagree & Neutral & Agree & $\begin{array}{c}\text { Strongly } \\
\text { agree }\end{array}$ \\
\hline $\begin{array}{l}\text { The holographic display of "Zhenhai building" is very } \\
\text { clear }\end{array}$ & 0 & 0 & $4.5 \%$ & $12 \%$ & $83.6 \%$ \\
\hline Holographic display has a strong sense of substitution & 0 & $13.5 \%$ & $4.5 \%$ & $19.4 \%$ & $62.7 \%$ \\
\hline $\begin{array}{l}\text { It's very convenient to watch holographic display with } \\
\text { naked eyes }\end{array}$ & 0 & 0 & $3 \%$ & $8.9 \%$ & $88.1 \%$ \\
\hline $\begin{array}{l}\text { The holographic display of "Zhenhai building" is very } \\
\text { intuitive }\end{array}$ & 0 & 0 & $3 \%$ & $13.4 \%$ & $83.6 \%$ \\
\hline $\begin{array}{l}\text { "Zhenhai building" holographic display supports multi } \\
\text { angle adjustment }\end{array}$ & 0 & 0 & $4.5 \%$ & $12 \%$ & $83.6 \%$ \\
\hline $\begin{array}{l}\text { I can quickly switch the display angle of Zhenhai } \\
\text { building }\end{array}$ & 0 & 0 & $1.5 \%$ & $7.5 \%$ & $91.0 \%$ \\
\hline The display of "Zhenhai building" is very smooth & 0 & $4.5 \%$ & $1.5 \%$ & $4.5 \%$ & $89.5 \%$ \\
\hline $\begin{array}{l}\text { The zoom in and zoom out function of Zhenhai building } \\
\text { is very useful }\end{array}$ & 0 & 0 & $4.5 \%$ & $9.0 \%$ & $86.6 \%$ \\
\hline $\begin{array}{l}\text { With voice explanation, I have a better understanding of } \\
\text { Zhenhai building }\end{array}$ & 0 & $4.5 \%$ & $1.5 \%$ & $10.4 \%$ & $83.6 \%$ \\
\hline
\end{tabular}




\section{CONCLUSION}

In this paper, holographic immersion technology is applied to educational display. The holographic display cabinet with high cost performance and flexible layout is used as museum educational display equipment. The landmark building "Zhenhai building" in Guangzhou is taken as the display object. Through the construction of three-dimensional model, mapping, baking light effect, shading output and other processes, the image of "Zhenhai building" is superimposed in the real scene to form a strong immersion effect.

The survey shows that the holographic education display of "Zhenhai building" is very vivid, simple and easy to use, with good stability, rich interactive means and obvious educational effect.

The main problems of holographic education display are that the production of display materials is difficult, the efficiency is low, and it is not suitable for the display theme with fast update and iteration.

\section{REFERENCES}

[1]Wang Yunxin, Wang Dayong et al. The application of digital holography in biomedical imaging and analysis[J]. Chinese laser, 2014, (2): 33-42. (In Chinese)

[2]Tie zhong. Research on digital collection and interactive display design of residential historic district -Taking Shikumen architectural cultural heritage protection as an example [J]. Decoration, 2015, (10): 134-135. (In Chinese)

[3]Lu Lu, Tian Feng, Dai Guozhong. A Study of the Multimodal Cognition and Interaction Based on Touch, Audition and Vision[J]. Journal of Computer-Aided Design \& Computer Graphics, 2014, 26(4):654-661. (In Chinese)

[4]Sharon Macdonald, The Politics of Display: Museums, Science, Culture, London and New York: Routledge, 1998, pp. 1-21.

[5]Yang Ruyuan, Yuan Quan, sun Youfu. Application of holographic virtual technology in modern display design [J]. Furniture and interior decoration, 2018, (11): 52-54. (In Chinese)

[6]E Buckley. Holographic Laser Projection[J], Journal of display technology, 2011, 7(3):135-140.

[7]Zhang Wanmao, Jiang Chunlin, Gan Jing. Journal of engineering drawings, $[\mathrm{J}]$. lighting technology in product realistic expression of the 2009 (2): 48-53. (In Chinese)

[8]Xue Weimin. Research on Affective on Virtual Human Interaction Based on Cognitive Mechanics[J]. Journal of Beijing Union University, 2010, 24(4):1-6. (In Chinese) 